\title{
Monitoring of long-lasting insecticidal nets (LLINs) coverage versus utilization: a community-based survey in malaria endemic villages of Central India
}

\author{
Kamaraju Raghavendra ${ }^{1 *+} @$, Mehul Kumar Chourasia ${ }^{2 \dagger}$, Dipak Kumar Swain², Rajendra M. Bhatt ${ }^{3}$,
} Sreehari Uragayala ${ }^{4}$, G. D. P. Dutta ${ }^{3}$ and Immo Kleinschmidt ${ }^{5}$

\begin{abstract}
Background: Despite the known effectiveness of long-lasting insecticidal nets (LLINS) in providing protection against malaria, high level of ownership and use are very difficult to achieve and maintain. Nearly 40,000 LLINs were distributed in 2014 as an intervention tool against malaria transmission in 80 villages of Keshkal sub-district in Chhattisgarh, India. This study assessed LLIN coverage, access, utilization pattern, and key determinants for the net use 1 year after mass distribution.

Methods: In 2015, a cross-sectional household survey was carried out in 80 study clusters (whole village or part of village). From each cluster, 40 households were randomly selected and interviewed using a structured questionnaire adapted from the malaria indicator survey of Roll Back Malaria guidelines. Information on demographic characteristics, LLIN ownership, and its use on the night before the survey, and physical condition of LLINs were recorded.

Results: 2970 households were interviewed with a total of 15,003 individuals present in the households during the night before the survey. Nearly $98 \%$ of households had at least one LLIN and $59.4 \%$ of the surveyed population reportedly used an LLIN the previous night. LLIN use varied from 41 to $94 \%$ between the study clusters. Nearly $89 \%$ of the LLINs were found in good physical condition (without holes). However, proportion of household with at least one LLIN per two persons was only 39\%.

Conclusion: Universal coverage of LLINs was inadequate in the study clusters making it difficult for all household members to use an LLIN. LLIN use varied between clusters and was highest in children under 5 years of age. Health education campaigns and creating awareness about the benefit of sleeping under the LLINs in providing protection against malaria is required not only to high risk groups of pregnant women and children below 5 years of age but all the members of the family to have an epidemiological impact of this intervention at the community level. Relatively high net use despite poor access to LLINs indicates an overall desire to use nets when they are available. The main barrier to increased use of nets is the low coverage at household level.
\end{abstract}

Keywords: Long-lasting insecticidal nets (LLINs), LLINs uses, LLINs coverage, Chhattisgarh, India

\footnotetext{
*Correspondence: kamarajur2000@yahoo.com

${ }^{\dagger}$ Kamaraju Raghavendra and Mehul Kumar Chourasia contributed equally

to this work

1 National Institute of Malaria Research (ICMR), Sector-8, Dwarka, New

Delhi 110077, India

Full list of author information is available at the end of the article
} 


\section{Background}

Use of long-lasting insecticidal nets (LLINs) is a widely implemented and cost-effective public health intervention tool for malaria control and prevention in most malaria endemic countries [1-3]. Systematic review suggests that universal LLIN coverage with adequate usage may reduce the incidence of clinical malaria by up to $50 \%$ in malaria endemic (stable) areas [4]. Among children under 5 years of age, LLINs provide up to $55 \%$ protective efficacy in preventing malaria attributed mortality $[5,6]$. Operational success can only be achieved when universal coverage is attained and at least $80 \%$ of bed nets are actually used by the community [7]. However, the impact on reduction of malaria varies by underlying transmission intensity and has not been established.

LLIN mass distribution campaigns and supplementary distribution through antenatal clinics and immunization services have largely been successful in achieving increased LLIN ownership and universal LLIN coverage in the population [8-13]. Several African studies have shown an apparent difference in adequate LLIN possession (one LLIN per two person) and LLIN use by the community [14-18]. Therefore, routine monitoring for LLIN use and regular community-tailored education and awareness campaigns may be vital to sustain the utilization and to optimize the protective effect of LLINs [12, 19].

In the past two decades, a number of studies, mostly from African continent, have explored various factors and determinants for decline in bed net use in the household as well as at the community level. The major reported factors for non-use were inadequate net availability, heat and discomfort due to sleeping under the net, absence of mosquito nuisance, seasonal variation, sleeping pattern and preferences for net uses among household members [16, 18, 20-23].

Since 2009, India has initiated scaling up of LLIN interventions under the National Vector Borne Disease Control Programme (NVBDCP) to control malaria in endemic states [24]. In 2016, an action plan for malaria elimination by 2030 has emphasized LLIN interventions and indoor residual spraying (IRS) of insecticide. Monitoring of LLIN access and use is needed at household and community levels to optimize the impact of LLIN based intervention and sustain effective malaria control in the region.

There is scant information on large-scale community based assessment studies on LLIN coverage and usage pattern post mass LLIN distribution under the national programme from the Indian sub-continent $[25,26]$. Limited studies have explored the factors which affect LLIN access and use and reasons for attrition in the Indian population especially among tribal inhabitants [27].
The main objective of the present study was to evaluate LLIN ownership, access, use and attrition rate in the tribal population in 80 study clusters (whole village or part of village) of Keshkal sub-district, Chhattisgarh, India, 1 year after mass distribution of LLIN. This study also investigated the factors affecting the LLIN use and reasons for non-use in the study population. This study was implemented as part of the research project on Implications of insecticide resistance (IIR) on malaria vector control [28].

\section{Methods}

\section{Study area and study design}

A clustered-sample, cross-sectional household survey was undertaken during August-November 2015, 1 year after mass LLIN distribution. The study was carried out in 80 study clusters of Keshkal $\left(20^{\circ} 5^{\prime} 1 \mathrm{~N}\right.$ and $\left.81^{\circ} 35^{\prime} 12 \mathrm{E}\right)$, a sub-district in Kondagaon district in Chhattisgarh state, India. Study villages are predominantly inhabited by the 'Gond' tribe and basic livelihood depends on subsistence agriculture, collection and selling of forest products, and manual labour. The major crop is paddy, cultivated during the monsoon season, starting from late-June to midOctober. Main malaria transmission season in the region overlaps with the cultivating season. Anopheles culicifacies is the primary vector of malaria in the study area.

\section{LLINs distribution}

PermaNet 2.0 , a deltamethrin $\left(55 \mathrm{mg} / \mathrm{m}^{2}\right)$ impregnated polyester LLIN, manufactured by Vestergaard Frandsen (Switzerland) were provided by the State Health Department for distribution in the study villages. A census of all the households was done in 2013. Based on census, household list with total family members was prepared and then number of nets a household would receive was determined. Project staff and field workers were trained for LLIN distribution and health education. In most of the villages, nets were distributed through a fixed point approach in Anganwadi centres (Children day care centres), schools, or Gram Panchayat (village council) buildings. All households were informed about LLIN distribution in their respective villages. However, if any household was missed during the distribution round due to the house being locked or due to the absence of adult members, additional mop-up rounds of distribution were made through door-to-door visits to ensure that no household was left without a net. By the end of distribution during November-December 2014, about 40,000 nets were distributed covering $\sim 80,000$ of population in all the villages. At the time of net distribution, a printed handbill in the local language on use and care of LLINs was provided. The content was also read to householders at opportune times during the follow 
up visits by the project personnel. High turnout of the community for receiving the nets was recorded. Based on census records, 99.5\% LLIN coverage was achieved barring inhabitants in locked houses despite mopping and an average of two LLINs [95\% confidence interval $(\mathrm{CI})=1.7-2.3$ ] per household was achieved. Outer polythene covers of LLINs were retained and along with the packing (HDPE sacs) material were sent for incineration in the bio-medical waste management plant to prevent environmental pollution and hazard.

Distribution of LLINs was done as per the national guidelines, i.e., 1 net for 2.5 persons [29] which was changed to 1 net per 2 persons [30]. Due to these revised criteria, the calculated LLIN coverage was reduced to $40.9 \%$ which created a shortfall of about 10,000 nets. Efforts made to procure the additional quantity of nets to improve the coverage were not achieved.

\section{Study questionnaires and variables}

A structured questionnaire adapted from Malaria Indicator Survey (2013) as per Roll Back Malaria (RBM) guidelines was used for evaluating compliance of LLIN among the individuals in the households and the effectiveness of the distribution [31]. The questionnaire consisted of three parts: general information; individual net access and compliance to LLIN use; and LLIN's physical integrity. The questionnaire was translated into Hindi and back translated into English to verify the validity of the translation. The questionnaire was pre-tested and piloted to identify any errors or misinterpretation due to wording or the translation.

\section{Study variable definitions and indicators}

The main outcome of interest was 'last night LLIN use', defined as the proportion of residents who reported to have slept under an LLIN the night preceding the survey. The following indicators were collected: (1) proportion of households with at least one LLIN; (2) proportion of households with at least one LLIN for every two people; (3) proportion of existing LLINs used the previous night; (4) proportion of population that slept under a LLIN the previous night; (5) proportion of children under 5 years old who slept under a LLIN the previous night. For this study, member of one household was defined as 'all the members residing under one roof and sharing a common cooking place.'

\section{Sample size calculation}

Two-stage cluster sampling design with 'household' as primary sampling units (PSUs) was used to select sample in the survey. Cluster level sampling frame was used to prepare the list of all the selected households. Furthermore, 40 households were sampled from each study cluster which were identified by systematic random sampling. A sample size was calculated for the precision of 5 and $50 \%$ of expected point estimate of the proportion of community residents sleeping under LLINs in the previous night, $95 \%$ confidence interval with assumption of $90 \%$ of response and design effect of 1.8 . Hence, a total of 3200 households from 80 study clusters were sampled during the survey.

\section{Study data collection}

Based on selected list, households were approached for the survey. The survey was carried out by skilled and trained project staff after a day of orientation and field training for conducting the activity. The interview procedure was described to the respondent before the start of the interview. Where a selected house was found locked, the next house was used as a replacement. Interviews were conducted within the premises of the respondent's house using Hindi or local language (Chhattisgarhi and Halbi dialects) for ease of communication.

\section{Data entry and statistical analysis}

All the data were entered twice in EpiData version 3 and statistical analysis was carried out in SPSS 20 version (IBM statistics, NY). Continuous variables were expressed as mean and standard deviation (SD) while categorical variables were expressed as number and proportion. The association between the outcome and independent variables was assessed using generalized estimating equations (GEE) to allow for clustering at village level. Study clusters were taken as subjects. 'LLIN use' was response variable in the model. Binomial distribution with logit link function and exchangeable correlation structure was selected for the GEE model. Study cluster variable was taken at the subject level. Firstly, in the univariate GEE model, all possible exposure variables such as literacy of head of the households, type of house, household size, and age of family members were included in the model. Then, in the final multivariate GEE model, all those variables that were significant in the univariate model were included. Tables were prepared with unadjusted and adjusted odds ratios (95\% confidence intervals) and respective $\mathrm{p}$ value (Table 3 ).

\section{Ethical clearance and informed consent}

Informed consent was obtained from the head of households to participate in the study at the time of LLINs distribution and during the data collection. This study was undertaken as a part of a WHO-coordinated multi-country project and ethical clearance was obtained from the Institutional Ethics Committee of National Institute of Malaria Research, India (ECR/NIMR/EC/2010/75). 


\section{Results}

Socio-demographic characteristics of study population A total of 2970 households with average household size (standard deviation) of $5.3 \pm 1.96$ persons were surveyed in 80 clusters. In the surveyed households, the mean age of head of the households was 48.9 years. Most of them were males $(83.5 \%)$ and nearly two-thirds had attended more than primary level of school (67.1\%). Among the surveyed households, in majority $(65.4 \%)$ of the houses, roofs were made up of clay tiles/tin/asbestos (Table 1).

The survey covered 15,800 residents with an average age of 27.7 years (SD \pm 18.3 ). Proportion of children under 5 years of age was $8.3 \%$, while female population contributed $51.2 \%$.

Table 1 Socio-demographic characteristics of households $(n=2970)$ and study participants $(n=15,800)$

\begin{tabular}{|c|c|c|}
\hline Variable name & Variable category & Frequency, $\mathrm{n}(\%)$ \\
\hline Age of head of household (in years) & Mean $( \pm S D)$ & $48.9( \pm 12.8)$ \\
\hline \multirow[t]{2}{*}{ Gender of head of household } & Male & $2479(83.5)$ \\
\hline & Female & $491(16.5)$ \\
\hline \multirow[t]{4}{*}{ Highest educational level of head of household } & None & $978(32.9)$ \\
\hline & Primary school & $1390(46.8)$ \\
\hline & Middle school & $351(11.8)$ \\
\hline & Secondary and higher & $251(8.5)$ \\
\hline Household size & Mean $( \pm S D)$ & $5.3( \pm 1.9)$ \\
\hline \multirow[t]{3}{*}{ Type of house (roof) } & Hut/thatched & $239(8.0)$ \\
\hline & Clay tile/tin/asbestos & $1942(65.4)$ \\
\hline & Pakka/RCC roof & 789 (26.6) \\
\hline \multirow[t]{3}{*}{ Age of household members (years) } & $<5$ & $1309(8.3)$ \\
\hline & $5-14$ & $2951(18.7)$ \\
\hline & $>14$ & $11,540(73.0)$ \\
\hline \multirow[t]{2}{*}{ Gender of household members } & Male & $7712(48.8)$ \\
\hline & Female & $8808(51.2)$ \\
\hline \multirow[t]{2}{*}{ Household members present last night } & Yes & $15,003(94.9)$ \\
\hline & No & $797(5.0)$ \\
\hline
\end{tabular}

Table 2 Net availability, access, type of bed nets, uses and attrition $(n=2970)$

\begin{tabular}{|c|c|c|}
\hline Variable name & Category & Frequency, $\mathrm{n}(\%)$ \\
\hline Households with at least one mosquito net & Yes & $2942(99.1)$ \\
\hline LLIN ownership (households with at least one LLIN) & Yes & $2923(98.4)$ \\
\hline \multirow[t]{4}{*}{ Number of LLINs ownership per $\mathrm{HH}$} & 1 & $602(20.3)$ \\
\hline & 2 & $1668(56.2)$ \\
\hline & 3 & $602(20.3)$ \\
\hline & $\geq 4$ & $51(1.7)$ \\
\hline \multirow[t]{2}{*}{ Total number of bed nets available in the surveyed $\mathrm{HH}(\mathrm{n}=7683)$} & LLIN & $5953(77.5)$ \\
\hline & Untreated net & $1730(22.5)$ \\
\hline Number of LLINs per HH & Mean $( \pm S D)$ & $2.0( \pm 0.74)$ \\
\hline Households with at least one LLIN for every two persons & Yes & $1148(38.7)$ \\
\hline \multirow[t]{2}{*}{ Last night bed net use by $\mathrm{HH}$ members } & LLIN users & $9388(59.4)$ \\
\hline & Untreated net users & $1156(7.3)$ \\
\hline \multirow[t]{3}{*}{ Use of LLINs the previous night by age group } & $<5$ years & $1018(81.2)$ \\
\hline & $5-14$ years & $1853(69.8)$ \\
\hline & $>14$ years & $6517(61.8)$ \\
\hline \multirow[t]{2}{*}{ Use of LLINs the previous night by age group by gender } & Male & $4479(63.9)$ \\
\hline & Female & $4909(65.9)$ \\
\hline LLIN with at least one hole (of any size) & Yes & $659 / 5953(11.2)$ \\
\hline Use to access ratio (\%) & & $59.4 / 98.4(60.4)$ \\
\hline
\end{tabular}


Net availability, access, type of bed nets and use

Overall, 98.4\% of surveyed households had at least one LLIN. $80 \%$ of households were in possession of two or more LLINs (79.7\%). In all, 5953 LLINs and 1730 untreated nets were present and physically observed in the surveyed houses during the survey. Only $38.7 \%$ of the household met the universal coverage criterion of 1 LLIN per two persons (Table 2).

Altogether, $59.4 \%$ of the population was reportedly using an LLIN the night before the survey, while $7.3 \%$ were using untreated nets. LLIN use was high among children under 5 years (81.2\%). Among all physically observed LLINs, $11.2 \%$ had at least one hole (of any size).

\section{Determinants associated with LLIN use in the study population}

Based on a univariate GEE model, strong to moderate associations were found between LLIN use and sociodemographic variables such as literacy of head of the households [odds ratio $(\mathrm{OR})=1.28,95 \%$ confidence interval $(\mathrm{CI})=1.1-1.5 ; \mathrm{p}=0.001]$, type of house (clay tile vs hut: $\mathrm{OR}=1.71,95 \% \mathrm{CI} 1.3-2.3 ; \mathrm{p}<0.001)$ household size $(1-2$ vs $>8:$ OR $=1.51,95 \%$ CI $1.1-2.1 ; \mathrm{p}=0.021)$ and age of family members $(2.67,2.3-3.1 ;<0.001)$. Additionally, a weak association was found between LLIN use and gender of household members (male vs female: $\mathrm{OR}=1.1,95 \% \mathrm{CI} 1.01-1.2 ; \mathrm{p}=0.014$ ). In the final multivariate GEE model, all the five explanatory variables including literacy of head of the households, type of house, age and gender of family members and persons per LLIN showed significant association with LLIN use (Table 3).
Reasons cited by the non-users for non-use of LLINs

Among the total de facto population, 27.2\% reported not to have used a net the night before the survey. Among non-users, $46 \%$ of the persons cited non-availability of LLIN as a major reason for not using LLIN followed by seasonal use of LLIN (7.5\%). Nearly, 14\% of non-users reported other means of protection such as fire, smoke, use of fan, etc. and nearly $7 \%$ perceived less mosquito density in the houses (Table 4).

\section{Discussion}

This study showed that $98.4 \%$ of the surveyed household had access to one LLINs and 59.4\% of the residents were using LLINs during the night before the survey. A high number of LLIN uses (81.2\%) among vulnerable age group of children $<5$ years of age was observed, followed by $69.8 \%$ among $5-14$ years of children. Similar LLIN use among high risk group in the same population has been previously observed [32]. Overall LLIN use among adults was lower than among children. This was mainly due to inadequate number of nets per household and the high focus on vulnerable age groups in the educational and awareness camps in the national malaria control programs. One other thing that is worth emphasizing is that this is an area that never had nets in the past, and there is therefore no long tradition of using LLIN, and yet people who have adequate access seem to be using them. Apart from that, by comparison to other studies, lower gender disparity in LLIN use (female vs male $=65.9$ vs 63.9 ) was observed in the study population [12, 33, 34].

Literacy of head of the households, type of house, and household size were among the key determinants of LLIN use in the study population. In particular, children

Table 3 Determinants associated with LLIN use among study population from households with $\geq 1$ LLIN (n = 14,455) per house

\begin{tabular}{|c|c|c|c|c|c|c|c|}
\hline Parameters & Category & $\begin{array}{l}\text { Last night LLIN } \\
\text { use } \mathrm{n}(\%)\end{array}$ & Total & $\begin{array}{l}\text { Unadjusted odds } \\
\text { ratio }(95 \% \mathrm{Cl})\end{array}$ & p value & Adjusted OR (95\% Cl) & $\mathrm{p}$ value \\
\hline \multirow{2}{*}{$\begin{array}{l}\text { Literacy of head of } \\
\text { household }\end{array}$} & No & $2929(61.1)$ & 4790 & 1 & - & - & - \\
\hline & Yes & $6459(66.8)$ & 9665 & $1.28(1.1-1.5)$ & 0.001 & $1.2(1.04-1.4)$ & 0.012 \\
\hline \multirow{3}{*}{$\begin{array}{l}\text { Age group of } \mathrm{HH} \\
\text { members (in years) }\end{array}$} & $>14$ & $6517(61.8)$ & 10,546 & 1 & - & 1 & - \\
\hline & $5-14$ & $1853(69.8)$ & 2655 & $1.43(1.3-1.6)$ & $<0.001$ & $1.5(1.4-1.7)$ & $<0.001$ \\
\hline & $<5$ & $1018(81.2)$ & 1254 & $2.67(2.3-3.1)$ & $<0.001$ & $3.18(2.7-3.7)$ & $<0.001$ \\
\hline \multirow{2}{*}{$\begin{array}{l}\text { Gender of } \mathrm{HH} \\
\text { members }\end{array}$} & Male & 4479 (63.9) & 7007 & 1 & - & 1 & - \\
\hline & Female & 4909 (65.9) & 7448 & $1.1(1.01-1.2)$ & 0.014 & $1.1(1.03-1.2)$ & 0.005 \\
\hline \multirow[t]{3}{*}{ Type of house } & Hut/thatched & $665(54.1)$ & 1230 & 1 & - & 1 & - \\
\hline & Clay tile/tin/asbestos & $6231(66.8)$ & 9327 & $1.71(1.3-2.3)$ & $<0.001$ & $1.09(0.96-1.2)$ & 0.209 \\
\hline & Pakka/RCC roof & $2492(63.9)$ & 3898 & $1.51(1.1-2.0)$ & 0.006 & $0.67(0.52-0.94)$ & 0.012 \\
\hline \multirow{3}{*}{$\begin{array}{l}\text { Number of person } \\
\text { per LLIN }\end{array}$} & $>4$ & 481 (42.9) & 639 & 1 & - & 1 & - \\
\hline & $2.1-4$ & $5794(64.8)$ & 8935 & $2.45(2.0-3.0)$ & $<0.001$ & $2.65(2.15-3.28)$ & $<0.001$ \\
\hline & $\leq 2$ & $3113(70.8)$ & 4400 & $3.21(2.58-4.01)$ & $<0.001$ & $3.75(2.98-4.72)$ & $<0.001$ \\
\hline
\end{tabular}

Subject level-study cluster $(n=80)$ 
under 14 years of age, households living in pakka/khaprel (cemented house with tiled roof) houses with family size $\leq 4$ members were more likely to use LLINs in the surveyed population (Table 3 ).

Odds of using LLINs were 0.67 times higher among the population residing in pakka type of houses as compared to those living in hut type of house structures. Sleeping arrangement and house structures are major determinants for LLIN use, possibly due to inadequate space and suitable places for hanging the nets in the hut type of houses $[35,36]$. Similarly, odds of using LLIN increased in families with decrease in family size in the study area. In addition, higher education level of the head of the household was significantly associated with increase in odds of sleeping under a LLIN (OR, 95\% CI $=1.2,1.04-1.4$; $\mathrm{p}=0.012$ ). Similar findings were reported by Ntuku et al. [13]. Likewise, larger households found to have lower net use was also reported in African studies [14-17].

After 1 year of distribution, fabric integrity was retained in $89 \%$ of total observed LLINs. A recent field study has reported durability of LLINs as of 2-3 years and after 2 years, more than half of LLINs usually fall in 'replacement category' [37].
Major behavioural determinants of non-use of LLIN were use of alternative mosquito control methods (14\%), low mosquito density (6.8\%), discomfort due to LLIN or not habitual of sleeping under the LLIN (6.8\%) apart from non-availability of LLINs (46.1\%). Similar determinants were also reported by earlier studies [18, 38, 39].

Despite high LLIN coverage (98.4\%), intra-household availability was lower; hence, additional distribution of LLINs in the study area was required. The current study has highlighted the call for of regular assessment of LLIN use, top-up LLIN distribution and concurrent awareness about use of LLIN by all age groups for equitable protection against malaria in the population living in endemic areas.

\section{Limitations}

This study has not assessed LLIN fabric integrity and survivorship. Hence, further follow-up studies on LLIN fabric integrity and survivorship is required to assess the net serviceable life and predict the timing of next round of LLIN distribution to maintain the adequate coverage at intra-household level.

Table 4 Various reasons cited for non-use of LLINs by non-users $(n=3937)$

\begin{tabular}{|c|c|c|c|}
\hline Sl. no & Non-use category & Major reported reasons & Frequency, $\mathrm{n}(\%)$ \\
\hline \multirow[t]{3}{*}{1.} & Technical & Inadequate space & $43(1.1)$ \\
\hline & & No place to hang the net & $12(0.3)$ \\
\hline & & Home maintenance/painting & $133(3.4)$ \\
\hline \multirow[t]{4}{*}{2.} & Discomfort & Heat & $26(0.7)$ \\
\hline & & Feel closed in & $44(1.1)$ \\
\hline & & Non-habitual & $251(6.4)$ \\
\hline & & Inconvenience & $5(0.1)$ \\
\hline \multirow[t]{4}{*}{3.} & Non-availability & Net not available & $1813(46.1)$ \\
\hline & & Net washed & $125(3.2)$ \\
\hline & & Net given away & $08(0.2)$ \\
\hline & & Net was torn/worn out & $49(1.2)$ \\
\hline \multirow[t]{2}{*}{4.} & Social & Slept elsewhere & $30(0.8)$ \\
\hline & & Due to guest at home & $9(0.2)$ \\
\hline \multirow[t]{2}{*}{5.} & Perceived mosquito density/malaria & Less mosquito density & $268(6.8)$ \\
\hline & & No malaria now & $9(0.2)$ \\
\hline \multirow[t]{4}{*}{6.} & Use of mosquito control methods & Using fire/smoke & $129(3.3)$ \\
\hline & & Using fans & $77(2)$ \\
\hline & & Using blankets & $292(7.4)$ \\
\hline & & Using coil/mosquito repellent & $6(0.2)$ \\
\hline \multirow[t]{4}{*}{7.} & Other & Use only during rainy season & $296(7.5)$ \\
\hline & & Different use of LLIN & $48(1.2)$ \\
\hline & & Do not know & $150(3.8)$ \\
\hline & & Other & $114(2.9)$ \\
\hline
\end{tabular}




\section{Conclusions}

Regular awareness and maintenance of universal coverage is necessary to sustain the optimal LLIN coverage and usages in the population especially in high risk groups such as children under 5 years of age and evaluation of LLIN attrition in the malaria endemic areas. Health education and awareness about benefit of continuous use of LLIN should not be limited to only high risk groups but all household members to achieve the impact of this intervention at the community level. Further, top up distribution of additional LLINs is required where initial coverage is not achieved as per the revised norm of one net per two persons. The key reason for non-use of nets remains lack of access to LLINs. This underscores the importance of mass distributions achieving universal coverage in each household, not just overall coverage.

\section{Abbreviations \\ LLINs: long-lasting insecticidal nets; IRS: indoor residual spraying; MIS: Malaria Indicator Survey; RBM: Roll Back Malaria; NVBDCP: National Vector Borne Disease Control Programme; IIR: implications of insecticide resistance; PHC: Pri- mary Health Centres; HHs: households; WHO: World Health Organization; SD: standard deviation; GEE: generalized estimating equation.}

\section{Authors' contributions}

$K R$, RMB, and MKC designed the study. MKC, KR, and RMB drafted the manuscript. MKC and KR have done the literature review and study protocol preparation. MKC, SU, GDP and DKS supervised and collected the data. MKC and IK analysed the data. KR, RMB, DKS, SU, GDP, and IK reviewed and helped to write the manuscript. All authors made intellectual input to the study. All authors read and approved the final manuscript.

\section{Author details}

${ }^{1}$ National Institute of Malaria Research (ICMR), Sector-8, Dwarka, New Delhi 110077, India. ${ }^{2}$ National Institute of Malaria Research (ICMR) IIR-WHO Project, Field Unit, Kondagaon, Chhattisgarh, India. ${ }^{3}$ National Institute of Malaria Research (ICMR), Field Unit, Lalpur, Raipur, Chhattisgarh, India. ${ }^{4}$ National Institute of Malaria Research (ICMR), Field Unit, Bangalore, Karnataka, India. ${ }^{5}$ Department of Infectious Disease Epidemiology, London School of Hygiene and Tropical Medicine, London, UK.

\section{Acknowledgements}

We express our gratitude towards all the study participants for their patience and valuable time. We would like to thank all the field workers, staff of NIMR, field unit Raipur and IIR Project staff, Kondagaon for their sincere efforts in data collection and data entry. We also sincerely thanks the Director, NIMR, New Delhi for constant support and encouragement.

\section{Competing interests}

The authors declare that they have no competing interests.

\section{Availability of data and materials}

The datasets used and analysed during the current study are available from the corresponding author on reasonable request.

\section{Consent for publication}

Not applicable.

\section{Ethics approval and consent to participate}

The study purpose and method was explained in the local language to all study participants and study related queries were addressed. A written informed consent was collected from the head of the households during LLIN distribution. This study was undertaken as a part of a WHO-coordinated multi-country project and ethical clearance was obtained from the Institutional Ethics Committee of National Institute of Malaria Research, India (ECR/ NIMR/EC/2010/75).

\section{Funding}

Funding was provided by the Bill and Melinda Gates Foundation (Grant number OPP 1062754) which had no role in the planning, study design, data collection or write up. This research forms part of a multi-country study coordinated by the Global Malaria Programme of the World Health Organization.

\section{Publisher's Note}

Springer Nature remains neutral with regard to jurisdictional claims in published maps and institutional affiliations.

Received: 13 June 2017 Accepted: 11 November 2017

Published online: 17 November 2017

\section{References}

1. Lim SS, Fullman N, Stokes A, Ravishankar N, Masiye F, Murray CJL, et al. Net benefits: a multicountry analysis of observational data examining associations between insecticide-treated mosquito nets and health outcomes. PLoS Med. 2011:8:e1001091.

2. Pulkki-Brännström A, Wolff C, Brännström N, Skordis-Worrall J. Cost and cost effectiveness of long-lasting insecticide-treated bed nets-a modelbased analysis. Cost Eff Resour Alloc. 2012;10:5.

3. WHO. Insecticide-treated mosquito nets: a WHO position statement. Geneva: Global Malaria Programme, World Health Organization; 2007. http://www.ivcc.com/sites/ivcc.mrmdev.co.uk/files/content/itnspospaperfinal.pdf. Accessed 15 Jan 2017.

4. Lengeler $C$. Insecticide-treated bed nets and curtains for preventing malaria. Cochrane Database Syst Rev. 2004;2:CD000363.

5. Killeen GF, Smith TA, Ferguson HM, Mshinda H, Abdulla S, Lengeler C, et al. Preventing childhood malaria in Africa by protecting adults from mosquitoes with insecticide treated nets. PLoS Med. 2007;7:e229.

6. Eisele TP, Larsen D, Steketee RW. Protective efficacy of interventions for preventing malaria mortality in children in Plasmodium falciparum endemic areas. Int J Epidemiol. 2010;39:88-101.

7. WHO. Methods for maintaining coverage with long-lasting insecticidal nets (LLINs). Geneva: World Health Organization, Global Malaria Programme; 2013. http://www.who.int/malaria/mpac/mpac_sp13_vcteg_ universal_Ilin_coverage_report.pdf. Accessed 15 Jan 2017.

8. Teklehaimanot A, Sachs JD, Curtis C. Malaria control needs mass distribution of insecticidal bednets. Lancet. 2007;369:2143-6.

9. Bennett A, Smith SJ, Yambasu S, Jambai A, Alemu W, Kabano A, et al. Household possession and use of insecticide-treated mosquito nets in Sierra Leone 6 months after a national mass-distribution campaign. PLoS ONE. 2012;7:e37927.

10. Tokponnon FT, Aholoukpe B, Denon EY, Gnanguenon V, Bokossa A N'Guessan R, et al. Evaluation of the coverage and effective use rate of long-lasting insecticidal nets after nation-wide scale up of their distribution in Benin. Parasites Vectors. 2013;6:265.

11. WHO. Recommendations for achieving universal coverage with longlasting insecticidal nets in malaria control. Geneva: World Health Organization, Global Malaria Programme; 2013. http://www.who.int/malaria/ publications/atoz/who_recommendation_coverage_llin/en/. Accessed 20 Jan 2017.

12. Wanzira H, Yeka A, Kigozi R, Rubahika D, Nasr S, Sserwanga A, et al. Longlasting insecticide-treated bed net ownership and use among children under 5 years of age following a targeted distribution in central Uganda. Malar J. 2014;13:185.

13. Ntuku HM, Ruckstuhl L, Emmanuel J, Réminiac J, Umesumbu SE, Bokota A, et al. Long-lasting insecticidal net (LLIN) ownership, use and cost of implementation after a mass distribution campaign in Kasaï Occidental Province, Democratic Republic of Congo. Malar J. 2017;16:22.

14. Baume CA, Marin MC. Intra-household mosquito net use in Ethiopia, Ghana, Mali, Nigeria, Senegal, and Zambia: are nets being used? Who in the household uses them? Am J Trop Med Hyg. 2007;77:963-71. 
15. Thwing J, Hochberg N, VandenEng J, Issifi S, Eliades MJ, Minkoulou E, et al. Insecticide-treated net ownership and usage in Niger after a nation-wide integrated campaign. Trop Med Int Health. 2008;13:827-34.

16. Otsemobor O, Ajayi O, Afolabi BM, Ajayi JJ, Turshak LG, Fatunmbi BS, et al. Determinants of long-lasting insecticidal nets distribution, ownership and use in the Federal Capital Territory, Nigeria-implications for malaria programmes. J Public Health Epidemiol. 2013;5:445-58.

17. Woyessa A, Deressa W, Ali A, Lindtjørn B. Ownership and use of long-lasting insecticidal nets for malaria prevention in Butajira area, south-central Ethiopia: complex samples data analysis. BMC Public Health. 2014;14:99.

18. Ingabire C, Rulisa A, Van Kempen L, Muvunyi C, Koenraadt C, Van Vugt M, et al. Factors impeding the acceptability and use of malaria preventive measures: implications for malaria elimination in eastern Rwanda. Malar J. 2015;14:136.

19. Korenromp EL, Miller J, Cibulskis RE, Kabir Cham M, Alnwick D, Dye C. Monitoring mosquito net coverage for malaria control in Africa: possession vs. use by children under 5 years. Trop Med Int Health. 2003:8:693-703.

20. Binka FN, Adongo P. Acceptability and use of insecticide impregnated bednets in northern Ghana. Trop Med Int Health. 1997;2:499-507.

21. Pulford J, Hetzel MW, Bryant M, Siba PM, Mueller I. Reported reasons for not using a mosquito net when one is available: a review of the published literature. Malar J. 2011;10:83.

22. Auta A. Demographic factors associated with insecticide treated net use among Nigerian women and children. N Am J Med Sci. 2012;4:40-4.

23. Xu J, Liao Y, Liu H, Nie R, Havumaki J. Use of bed nets and factors that influence bed net use among Jinuo ethnic minority in Southern China. PLOS ONE. 2014;9:e103780.

24. NVBDCP 2016. National Framework for Malaria Elimination in India (20162030). Directorate of National Vector Borne Disease Control Programme (NVBDCP), Ministry of Health \& Family Welfare, Government of India. http://nvbdcp.gov.in/Doc/National-framework-for-malaria-eliminationin-India-2016\%E2\%80\%932030.pdf. Accessed 3 Dec 2016.

25. Anuse SS, Sahu SS, Subramanian S, Gunasekaran K. Usage pattern, physical integrity \& insecticidal efficacy of long lasting insecticidal nets in Odisha State, India. Indian J Med Res. 2015;142:71-8.

26. Mukhopadhyay DK, Basu SS, Roy D, Das N, Akbar F, Sarkar GN. Netting the malaria menace: distribution and utilization of long-lasting insecticidal net in a malaria endemic area in Bankura, West Bengal. J Vector Borne Dis. 2016;53:23-9.

27. Sood RD, Mittal PK, Kapoor N, Razdan RK, Dua VK, Dash AP. Community awareness, perceptions, acceptability and preferences for using LLIN against malaria in villages of Uttar Pradesh, India. J Vector Borne Dis. 2010;47:243-8

28. Kleinschmidt I, Mnzava AP, Kafy HT, Mbogo C, Bashir Al, Bigoga J, et al. Design of a study to determine the impact of insecticide resistance on malaria vector control: a multi-country investigation. Malar J. 2015;14:282.
29. Action plan for scaling up Long Lasting Insecticidal Nets for malaria control in India. Directorate of National Vector Borne Disease Control Programme (NVBDCP), Ministry of Health and Family Welfare, Govt. of India. 2009. http://www.nvbdcp.gov.in/Doc/LLIN-Action-Plan-2009.pdf. Accessed 5 Sep 2015.

30. Operational Manual for Malaria Elimination in India. Directorate of National Vector Borne Disease Control Programme (NVBDCP), Ministry of Health and Family Welfare, Govt. of India. 2016. http://www.nvbdcp.gov. in/Doc/Operational-Manual-Malaria-2016-Version-1.pdf. Accessed 5 May 2017.

31. Household Survey Indicators for Malaria Control. Roll Back Malaria Monitoring and Evaluation Reference Group Survey and Indicator Task Force. 2013. http://www.rollbackmalaria.org/files/files/resources/tool_HouseholdSurveylndicatorsForMalariaControl.pdf. Accessed on 10 Jan 2015.

32. Chourasia MK, Raghavendra K, Kleinschmidt I, Bhatt RM, Swain DK, Knox TB, et al. Impact of long-lasting insecticidal nets on prevalence of subclinical malaria among children in the presence of pyrethroid resistance in Anopheles culicifacies in Central India. Int J Infect Dis. 2017;57:123-9.

33. Ter Kuile FO, Terlouw DJ, Phillips-Howard PA, Hawley WA, Friedman JF, Kolczak WS, et al. Impact of permethrin-treated bed nets on malaria and all-cause morbidity in young children in an area of intense perennial malaria transmission in western Kenya: cross-sectional survey. Am J Trop Med Hyg. 2003;68:100-7.

34. Garley AE, Ivanovich E, Eckert E, Negroustoueva S, Yazoume Y. Gender differences in the use of insecticide-treated nets after a universal free distribution campaign in Kano State, Nigeria: post-campaign survey results. Malar J. 2013;12:119.

35. Kateera F, Ingabire CM, Hakizimana E, Rulisa A, Karinda P, Grobusch MP, et al. Long-lasting insecticidal net source, ownership and use in the context of universal coverage: a household survey in eastern Rwanda. Malar J. 2015;14:390.

36. I washita H, Dida G, Futami K, Sonye G, Kaneko S, Horio M, et al. Sleeping arrangement and house structure affect bed net use in villages along Lake Victoria. Malar J. 2010;9:176.

37. Hakizimana E, Cyubahiro B, Rukundo A, Kabayiza A, Mutabazi A, Beach R, et al. Monitoring long-lasting insecticidal net (LLIN) durability to validate net serviceable life assumptions in Rwanda. Malar J. 2014;13:344.

38. Chourasia MK, Abraham VJ, John J. Household training vs. mass campaigns: a better method of health communication for preventing malaria. Trop Dr. 2014:44:196-200.

39. Alaii JA, Hawley WA, Kolczak MS, terKuile FO, Gimnig JE, Vulule JM, et al. Factors affecting use of permethrin-treated bed nets during a randomized controlled trial in western Kenya. Am J Trop Med Hyg. 2003;68:137-41.

\section{Submit your next manuscript to BioMed Central and we will help you at every step:}

- We accept pre-submission inquiries

- Our selector tool helps you to find the most relevant journal

- We provide round the clock customer support

- Convenient online submission

- Thorough peer review

- Inclusion in PubMed and all major indexing services

- Maximum visibility for your research

Submit your manuscript at www.biomedcentral.com/submit 